\section{NEW INITIATIVES MAKE DENTISTRY SAFER FOR ANXIOUS AND VULNERABLE CHILDREN AND YOUNG PEOPLE}

Two important changes which will help promote the welfare of young dental patients have been welcomed by the British Society of Paediatric Dentistry (BSPD).

The use of conscious sedation for the treatment of anxious patients is vital for paediatric dentists and BSPD has been concerned for some time at the regional inequalities in accessing conscious sedation services.

The new national standards have been produced by the Intercollegiate Advisory Committee for Sedation in Dentistry (IACSD) and define the education and training required by those who work in sedation teams, whether they are dentists, doctors, nurses or dental care professionals as well as the settings where conscious sedation should take place.

Of significance to paediatric dentistry is that children under 12 years whose oral health needs cannot be met with care under local analgesia and inhalation sedation should now be referred to a specialist sedation team for assessment ${ }^{1}$.

Dr Janice Fearne, President of the BSPD, welcomed the improvement in patient safety that the new standards would help bring about.

Dr Fearne said: 'BSPD welcomes the strong focus on patient safety and recognises that our challenge now is to work with other special interest groups and those commissioning paediatric dental sedation services to support the implementation of these important recommendations.'

She said BSPD looked forward to working with the Dental Sedation Teachers Group and Consultant anaesthetist colleagues to ensure that the requirements of the new standards which relate to children are swiftly met.

The second important change is from the General Dental Council (GDC) which has announced that 'safeguarding children and young people' is to be included as a recommended continuing professional development (CPD) topic for dental professionals.

1 A specialist sedation team should comprise clinicians with - to quote from the document - skills equivalent to and expected of specialists or consultants in paediatric dentistry, working alongside those having skills equivalent to and expected of a consultant in anaesthesia competent in sedation for dentistry using advanced sedation techniques or elective general anaesthesia (GA), in a facility with services equivalent to an NHS Acute Trust.

\section{YOUR VIEWS ON THE NEXT NHS...}

The second NHS Confidence Monitor - a survey designed to capture how confident the profession are in the future of NHS dentistry - is now open for dentists to take part and share their views.

The first survey was conducted at the end of 2014 and is being repeated to monitor how confidence levels ebb and flow as new information about the contract reforms emerges and the selected prototype practices reveal their thoughts and findings on the potential new systems. The results will then help to provide a snapshot of how the profession perceives the future of NHS dentistry.

The survey explores the profession's thoughts on the future of:

- Career prospects

- Remuneration levels

- Getting the balance of treatment versus prevention within the NHS right

- The ability of the team to work effectively within the NHS.

Among other findings, the first survey revealed that $39 \%$ of the respondents asked were less confident about their career prospects within NHS dentistry over the next 12 months than they were a year ago.

Commenting on the opportunities the survey presents, Eddie Crouch, Vice Chair of the British Dental Association Principal Executive Committee, said: 'It will be very interesting to see how confidence levels in NHS dentistry have changed, particularly in light of the General Election, and I look forward to the results. I hope to see even more NHS dentists taking part in this survey so the profession has a greater insight into the possible future effect of NHS dentistry

As an NHS dentist, how do you feel about the future of dentistry? To have your say and help to inform your colleagues, please visit https://www.surveymonkey.com/s/NHSConfidenceMonitor

\section{How Dld Is Your Mouth?}

A new survey from UltraDEX reveals that in the UK our smile is officially our beauty blind spot. While $89 \%$ of people think that bad teeth can make a person look older, $40 \%$ of people admitted that they have never considered whether their smile could be ageing them.

We're all aware of the importance of healthy eating and exercise to stay young and we spend millions on antiageing skincare products, but UltraDEX have worked with leading dentists who say we overlook how our ageing teeth impact on how well we look, and they have come up with an ageing assessment.

What happens to teeth as we age?

Everyday wear and tear and the natural ageing process takes a toll on our teeth and gums, given all the chewing, crunching, biting and gnashing they do.

Contrary to what many people assume, teeth do not necessarily become more brittle with age, but tiny flaws, chips and cracks develop on our teeth over time. Stains appear where there is organic build-up of plaque, enamel erodes, gums recede and teeth can shift as we lose bone. The risk of gum problems increase with age as pockets form at the gum line where bacteria can grow. Sugary and starchy foods and carbonated sugary drinks are some of the biggest threats to teeth, as carbohydrates ferment, causing the bacteria in the mouth to produce enamel eating acids.

The best way to control ageing teeth and subsequent problems is prevention. Healthy teeth can immediately make you look younger and more attractive. How old is your mouth? To find out take the online test at www.ultraDEX.co.uk/HOIYM.

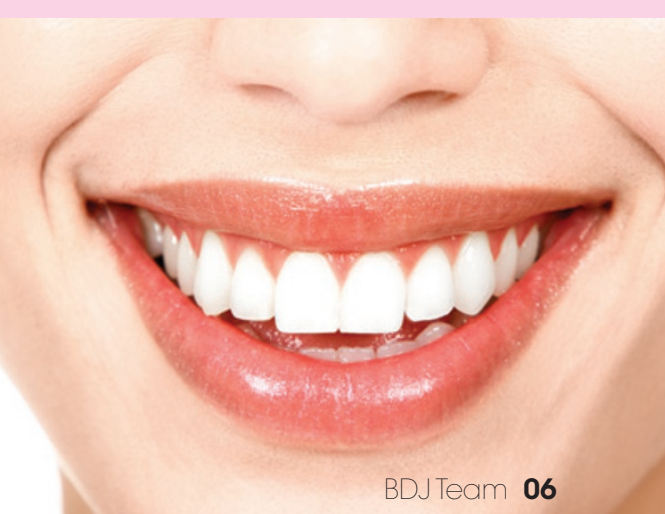

